\title{
ICT knowledge, utilization and perception among healthcare providers at National Hospital Abuja, Nigeria
}

\author{
Ibrahim Taiwo Adeleke ${ }^{1,2, ~ *, ~ A d e j o k e ~ A b i o l a ~ S a l a m i ~}{ }^{3,4}$, Moses Achinbee ${ }^{1}$, Tony Chucks Anamah ${ }^{1}$, \\ Ibrahim Babaminin Zakari ${ }^{1}$, Muhammad Hassan Wasagi ${ }^{1}$
}

${ }^{1}$ Department of Health Information, Federal Medical Centre, Bida, Nigeria

${ }^{2}$ Centre for Health \& Allied Researches, Bida, Nigeria

${ }^{3}$ Health Informatics Research Initiatives in Nigeria, Bida, Nigeria

${ }^{4}$ Department of Health Records, National Hospital, Abuja, Nigeria

\section{Email address:}

ibratadeleke_aliseyin@yahoo.com (I. T. Adeleke), adejokeadeyemi636@yahoo.com (A. A. Salami), achinbee@yahoo.com (M. Achinbee), tonimah33@yahoo.com (T. C. Anamah), talk2babaminin@yahoo.com (I. B. Zakari), balawasagi@gmail.com (M. H. Wasagi)

\section{To cite this article:}

Ibrahim Taiwo Adeleke, Adejoke Abiola Salami, Moses Achinbee, Tony Chucks Anamah, Ibrahim Babaminin Zakari, Muhammad Hassan Wasagi. ICT knowledge, Utilization and Perception among Healthcare Providers at National Hospital Abuja, Nigeria. American Journal of Health Research. Special Issue: Health Information Technology in Developing Nations: Challenges and Prospects Health Information Technology. Vol. 3, No. 1-1, 2015, pp. 47-53. doi: 10.11648/j.ajhr.s.2015030101.17

\begin{abstract}
Background: Healthcare system in Nigeria is moving towards digitalization especially in the management of patients' health information, with a view to harmonizing medical care practice for improved healthcare quality. Information and communication technology (ICT) has transformed the way people collaborate, identify potential collaborators or friends, communicate with each other, and identify information that is relevant to their practice. Rationale: Thus, ICT has been identified as one measure to ensure these emerging trends in the Nation's healthcare systems. Design/objectives: This study deployed a cross-sectional structured questionnaire to determine ICT knowledge and utilization among healthcare providers at National Hospital Abuja $(n=271)$. Methods: We devised stratified random sampling in the recruitment of participants. Result: It was found that profession, possession of a laptop computer, age and sex were associated with knowledge, utilization and perception of ICT. Most participants were advanced in the use of electronic mail (51.8\%) and the Internet (47.1\%) mostly acquired through self-efforts (46.5\%). However, a greater portion of the participants exhibited poor knowledge of database management $(47.8 \%)$ and statistical analysis package $(46.3 \%)$. The vast majority have used computer $(95.0 \%)$ and the Internet (93.6\%) for more than 3 years and many (86.2 percent) expressed a desire for further ICT training. Virtually, all participants in this study opined that ICT will improve medical care quality but some anticipated concerns over medical confidentiality as ICT becomes widely adopted in the country's healthcare systems. Aside their poor skill in database design and statistical analysis software, healthcare providers at National Hospital, Abuja possessed good knowledge and disposition towards ICT especially for the enhancement of their professional practice and for public health quality improvement. They indicated interest in further ICT training in order to enhance their information sources for an improved practice. It would be worthwhile to enrich their sources of information in order to improve public health.
\end{abstract}

Keywords: Healthcare Providers, Healthcare Systems, Health Information, Health Information Technology, ICT, Nigeria

\section{Introduction}

Information and communication technology (ICT) is often used as an extended synonym for information technology [1]. It is a more specific term that stresses the role of unified communications and the integration of communications. It comprises of computing technology, the Internet and other accessories which enable users to access, store, transmit, and manipulate information. Cruickshank [2] established that peoples' attitude towards computer and computerization becomes more favourable as their experience of computers and computer technologies increases. In line with this assertion, Fairley [3] opined that the rapid advances in userfriendly interfaces of the computer have lessened the need to know the intricacies of how the machines work. Similarly, the Internet is a global system of interconnected computer 
networks that uses the standard Internet protocol suite to serve billions of users worldwide [4]. It shares its history with the development of electronic computers in the $1950 \mathrm{~s}$ and was first introduced to the public by the University of California, Los Angeles [5].

The increasing processing power of ICT especially, in portable devices has led to the development and linking together of services that would have been hard to imagine only a few years back. Asangansi et al [6] reported that computer as the major information technology tool has transformed information and data handling processes in all fields of endeavours. ICT has been described as an invaluable tool to good healthcare information management [7-9] especially, with the reported data quality problems [10] in the paper-based systems. It is a panacea for improved healthcare quality [7-9], and it has the potential to transform the current healthcare systems to the benefit of both the provider and consumer and for an improved public health [7-9]. ICT infrastructures are not a vaccine, food or a drug. They therefore do nothing directly themselves to prevent or treat diseases or poverty. They are a tool for conveying information. This may be directly to individuals such as patients/clients; or by sharing between healthcare professionals i.e. training and management, or as a form of policy directives. Computer technology has been adjudged by both healthcare experts and healthcare consumers as having critical roles to play in the transformation of healthcare services [11].

Generally, the field of medicine and medical practice require the use of ICT for support in information processing, decision making and records keeping [6]. In 2013, Wheatley [12] reported that the deployment of information technology in healthcare management has provided a mechanism for promoting greater reliability in healthcare quality. The evolution and rapid advancement of ICT products has transformed modern healthcare system in the areas of interaction and communication with colleagues and consumers, training and retraining of healthcare providers, storage and retrieval of up-to-date health information and it has impacted patient management[13]. Wheatley [12] also reported that the computer supports the practice of high quality evidence-based medicine, as well as continuous learning and improved experience. Dee [14] and Edwards et al [15] suggested that healthcare providers require immediate access to high quality answers to patients' care questions at every contact. Lack of such quality information may hinder knowledge-based healthcare services delivery [16]. A study [6] reported that ICT has been used to manage patients at a distance (telemedicine) and was used to manage hospitals and their patients' health records (electronic health records).

Similarly, the availability of ICT has provided the possibility of immediate and unprecedented access to the most recent and reliable results of clinical research and health information in everyday medical practice in developed countries [17-18]. Widespread adoption of ICT is a key strategy to meet the challenges facing health systems internationally of increasing demands, rising costs, limited resources and workforce shortages. Despite the rapid increase in ICT investment, uptake and acceptance has been slow and the benefits fewer than expected. For example, Kale [19] established that most healthcare professionals in developing countries had inadequate access to information and that the little information available to them was often unreliable and irrelevant. Similarly, Dorsch [20] submitted that rural healthcare providers were constrained by stemming barriers in spite of the fact that they needed basic information like their colleagues in the urban centres.
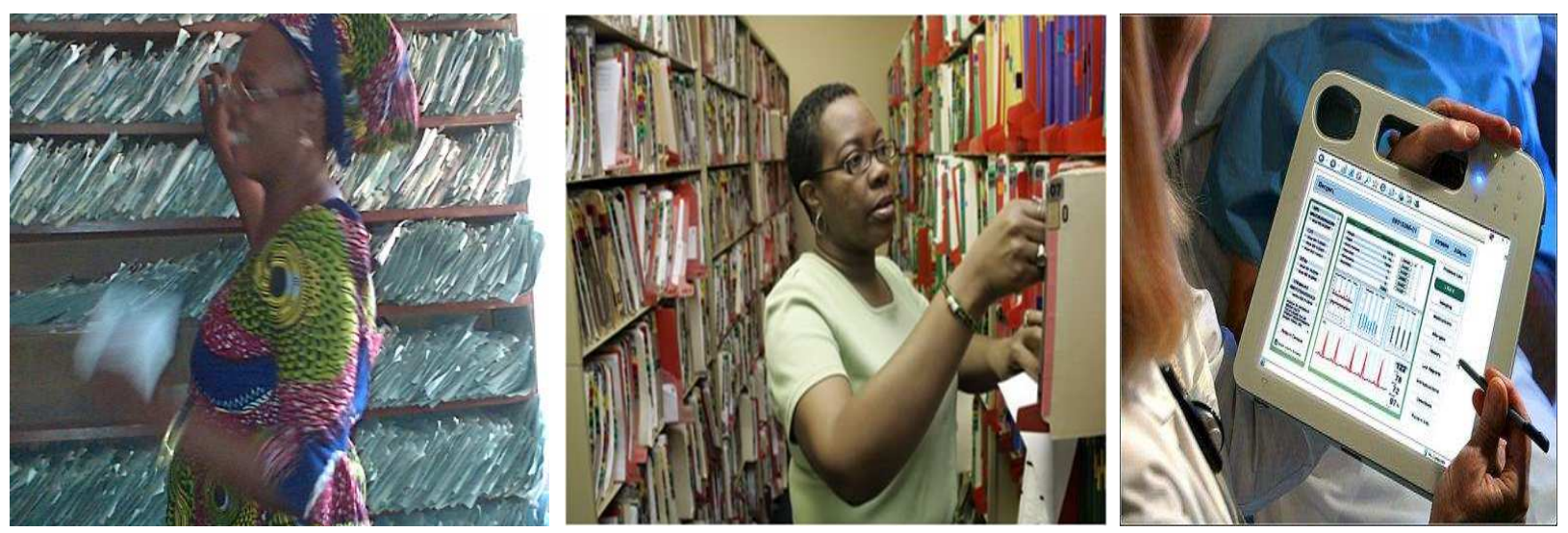

Fig. 1. L-R: A typical Nigerian paper-based health records system, manual filing in developed nation and a glimpse into an electronic health records system aided by ICT.

\subsection{Aim of the Study}

Access to healthcare information has become a key international development issue especially among healthcare professionals and the need to implement health information technology (HIT) has become a paramount issue in healthcare systems in Nigeria. However, very few studies exist that illustrate the utilization assessment of ICT among healthcare professionals in Nigeria and there is need to determine the extent especially, at National Hospital, Abuja which is one of the apex centres of possible implementations of HIT. Therefore, this study determined knowledge, utilization and perceptions of ICT among healthcare professionals at National Hospital Abuja, Nigeria. 


\section{Methods}

\subsection{Background to the Study Area}

The study was carried out at National Hospital Abuja, Nigeria. The hospital was originally designed in 1999 to cater for women and children in the West-African sub-region before the expansion of its scope to accommodate men in May 2000. The hospital though with 200 beds, has capacity for 500 beds. The hospital has staff strength of 1,850 as at the time of the study.

\subsection{Study Design}

This is a cross-sectional study of five key informationdriven and information-intensive professional groups in the hospital.

\subsection{Study Population}

Relevant stakeholders eligible for this study include 452 nurses, 304 doctors, 63 HIM professionals, 54 medical laboratory scientists and 47 pharmacists.

\subsection{Data Collection Tools}

The questionnaire was developed by the authors from review of relevant literatures. The tool is divided into five basic sections that delineate knowledge and skills in ICT, the use of computers and the Internet, perceived effects of ICT on health, participants' demographic parameters and possession of laptop, email and the use of social media. Data collection exercise took place between $24^{\text {th }}$ January and $5^{\text {th }}$ March 2014.

\subsection{Sampling Technique and Sample Size}

The study deployed stratified random sampling method. From the study population above, the total number of professionals targeted were 920 which include; 452 nurses, 304 doctors, 63 HIM professionals, 54 medical laboratory scientists and 47 pharmacists. Online sample size calculation software (www.surveysystem.com/sscalc.htm) was used to compute the sample size. The computed sample size was 271 which formed the number of recruited participants. As such, each group sample size is calculated as a ratio of the total population. An attrition rate of $10 \%$ was applied. In effects, we recruited 133 nurses, 90 doctors, 19 HIM professionals, 16 medical laboratory scientists and 14 pharmacists.

\subsection{Inclusion and Exclusion Criteria}

All healthcare professionals who fall into the target groups irrespective of their ranks were given equal opportunities to participate.

\subsection{Data Analysis and Management}

The statistical software SPSS V16.0 (2007) was used to analyze the data. Categorical data was expressed as proportions and percentages while continuous variables, were expressed as mean \pm standard deviation. Association between categorical variables was expressed using Chi square $(\chi 2)$ and test of statistical significance ( $p$-value) was set at $p=0.05$.

\subsection{Ethics}

Informed consent was explained in writing and obtained from all participants.

\section{Results}

\subsection{Participants' Characteristics}

Of the 271 questionnaires distributed, 260 (95.9\%) were returned. Among these participants, 143, (55.0\%) were females and $187(71.9 \%)$ of them were forty years old or below, with a Mean age of $35 \pm 9$ years. Nurses alone constituted nearly half,121 (46.5\%) of the participants, with $90 \quad(34.6 \%)$ doctors, $19 \quad(7.3 \%)$ health information management professionals, $16(6.2 \%)$ medical laboratory scientists and 14 (5.4\%) pharmacists.

\subsection{ICT Knowledge, Skills and Utilization among Participants}

Tables 1 and 2 illustrate knowledge and utilization of ICT among the diverse professional participants. Of all the participants, $129(51.8 \%)$ were advance in the use of electronic mail with HIM professionals and medical laboratory scientists leading $(100 \%)$. This was closely followed by those who have ability to search the Internet (121, 47.1\%) with HIM professionals leading (100\%) followed by doctors $(98.9 \%)$. The majority possess considerably average knowledge and skills in the use of word processor i.e. Microsoft Word (111, 42.9\%), with HIM professionals and medical laboratory scientists in the lead. However, many of the participants reported that they could not design (setting database criteria) database management i.e. Microsoft Access $(122,47.8 \%)$ and that they could not use statistical analysis software package $(118,46.3 \%)$. This poor knowledge and skills in database design and statistical analysis was high (21.4) among the pharmacists. Participants mostly obtained their skills through self-efforts $(46.5 \%)$ and from school (37.9\%), and they overwhelmingly indicated interests for further training in computer $(86.2 \%)$ and the Internet $(83.1 \%)$. Profession had statistical significance on knowledge $(\chi 2=75.54 ; p=.001)$ in word processing and sex had significance on skill $(\chi 2=32.48 ; p=.000)$ to use word processor. On ICT utilization, the vast majority of participants have used computer $(95.0 \%)$ and the Internet $(93.6 \%)$ for more than three years. Profession was associated with participants' perception of ICT $(\chi 2=33.26 ; p=.032)$ and possession of laptop had significance on utilization of the Internet $(\chi 2=107.8 ; p=.000)$. All doctors possessed a laptop computer, all HIM professionals have used social media and $28.6 \%$ of pharmacists have never used the Internet. 
Table 1. ICT knowledge, skills and utilization among participants

\begin{tabular}{|c|c|c|c|c|c|}
\hline & $\mathbf{N}$ & Advanced n (\%) & Average n (\%) & Basic n (\%) & No knowledge n (\%) \\
\hline \multicolumn{6}{|l|}{ ICT knowledge and skills } \\
\hline Word processing (Microsoft Word) & 259 & $72(27.8)$ & $111(42.9)$ & $69(26.6)$ & $7(2.7)$ \\
\hline Spread sheet (Microsoft Excel) & 258 & $30(11.6)$ & $96(37.2)$ & $114(44.2)$ & $18(7.0)$ \\
\hline PowerPoint presentation (Microsoft PowerPoint) & 259 & $67(25.9)$ & $82(31.7)$ & $84(32.4)$ & $26(10.0)$ \\
\hline Database management (Microsoft Access) & 255 & $22(8.6)$ & $49(19.2)$ & $102(40.0)$ & $82(32.2)$ \\
\hline Database design using Microsoft Access & 255 & $15(5.9)$ & $36(14.1)$ & $82(32.2)$ & $122(47.8)$ \\
\hline Internet search & 257 & $121(47.1)$ & $90(35.0)$ & $38(14.8)$ & $8(3.1)$ \\
\hline Electronic mailing & 249 & $129(51.8)$ & $81(32.5)$ & $30(12.0)$ & $9(3.6)$ \\
\hline Statistical analysis (e.g. SPSS, STATA, EpiInfo) & 255 & $11(4.3)$ & $38(14.9)$ & $88(34.5)$ & $118(46.3)$ \\
\hline $\begin{array}{l}\text { Computer file management (e.g. save, delete, copy, edit, } \\
\text { paste, merge, find etc.) }\end{array}$ & 258 & $86(33.3)$ & $97(37.6)$ & $60(23.3)$ & $15(5.8)$ \\
\hline Setting up computer system and install software & 258 & $48(18.6)$ & $54(20.9)$ & $76(29.5)$ & $80(31.0)$ \\
\hline Utilization of ICT among participants & $N$ & Yes & $\%$ & No/unsure & $\%$ \\
\hline Have used computer for more than three years & 259 & 246 & 95 & 13 & 5.0 \\
\hline Have used the Internet for more than three years & 250 & 234 & 93.6 & 16 & 6.4 \\
\hline $\begin{array}{l}\text { Used computer for more than three times in the last one } \\
\text { month }\end{array}$ & 243 & 211 & 86.8 & 32 & 13.2 \\
\hline $\begin{array}{l}\text { Used the Internet for more than three times in the last one } \\
\text { month }\end{array}$ & 232 & 198 & 85.3 & 34 & 14.7 \\
\hline Never used computer & 216 & 19 & 8.8 & 197 & 91.2 \\
\hline Never used the Internet & 206 & 20 & 9.7 & 186 & 90.3 \\
\hline Possess email & 259 & 254 & 98.1 & 5 & 1.9 \\
\hline Possess a laptop computer & 259 & 234 & 90.3 & 25 & 9.7 \\
\hline Have used social media & 256 & 245 & 95.7 & 11 & 4.3 \\
\hline
\end{tabular}

Table 2. ICT knowledge and utilization among professionals

\begin{tabular}{|c|c|c|c|c|c|}
\hline & $\begin{array}{l}\text { Nursing }(n=121) \\
\mathrm{n}(\%)\end{array}$ & $\begin{array}{l}\text { Medicine/Surgery } \\
(n=90) \mathrm{n}(\%)\end{array}$ & $\begin{array}{l}\text { HIM profession } \\
(n=19) \mathrm{n}(\%)\end{array}$ & $\begin{array}{l}\text { Medical laboratory } \\
\text { science }(n=16) \mathrm{n}(\%)\end{array}$ & $\begin{array}{l}\text { Pharmacy }(n=14) \\
\text { n }(\%)\end{array}$ \\
\hline \multicolumn{6}{|l|}{ ICT knowledge and skills } \\
\hline Word processing (Microsoft Word) & $116(95.9)$ & $89(98.9)$ & $19(100)$ & $16(100)$ & $12(85.7)$ \\
\hline Spread sheet (Microsoft Excel) & $106(87.6)$ & $88(97.8)$ & $18(94.7)$ & $16(100)$ & $12(85.7)$ \\
\hline $\begin{array}{l}\text { PowerPoint presentation (Microsoft } \\
\text { PowerPoint) }\end{array}$ & $101(83.5)$ & $87(96.7)$ & $17(89.5)$ & $16(100)$ & $12(85.7)$ \\
\hline Database management (Microsoft Access) & $76(62.8)$ & $64(71.1)$ & $16(84.2)$ & $11(68.7)$ & $6(42.9)$ \\
\hline Database design & $54(44.6)$ & $52(57.8)$ & $13(68.4)$ & $11(68.7)$ & $3(21.4)$ \\
\hline Internet search & $114(94.2)$ & $89(98.9)$ & $19(100)$ & $15(93.8)$ & $12(85.7)$ \\
\hline Electronic mailing & $105(86.6)$ & $89(98.9)$ & $19(100)$ & $16(100)$ & $11(78.6)$ \\
\hline $\begin{array}{l}\text { Statistical analysis (e.g. SPSS, STATA, } \\
\text { EpiInfo) }\end{array}$ & $48(39.9)$ & $69(57.0)$ & $9(47.4)$ & $8(50.0)$ & $3(21.4)$ \\
\hline $\begin{array}{l}\text { Computer file management (e.g. save, } \\
\text { delete, copy, edit, paste, merge, find etc.) }\end{array}$ & $109(90.1)$ & $89(97.8)$ & $19(100)$ & $16(100)$ & $10(71.4)$ \\
\hline $\begin{array}{l}\text { Setting up computer system and install } \\
\text { software }\end{array}$ & $64(52.9)$ & $75(83.3)$ & $15(78.9)$ & $15(93.8)$ & $9(64.3)$ \\
\hline \multicolumn{6}{|l|}{ Utilization of ICT } \\
\hline Possess email & $116(95.9)$ & $89(98.9)$ & $19(100)$ & $16(100)$ & $14(100)$ \\
\hline Possess a laptop computer & $98(81.0)$ & $90(100)$ & $17(89.5)$ & $16(100)$ & $13(92.9)$ \\
\hline Have used social media before & $111(91.7)$ & $86(95.6)$ & $19(100)$ & $16(100)$ & $13(92.9)$ \\
\hline $\begin{array}{l}\text { Have used computer for more than three } \\
\text { years }\end{array}$ & $111(91.7)$ & $88(97.8)$ & $18(94.7)$ & $15(93.8)$ & $14(100)$ \\
\hline $\begin{array}{l}\text { Have used the Internet for more than three } \\
\text { years }\end{array}$ & $101(83.5)$ & $86(95.6)$ & $18(94.7)$ & $15(93.8)$ & $14(100)$ \\
\hline Never used computer & $9(7.4)$ & $7(7.8)$ & $0(0)$ & $0(0)$ & $3(21.4)$ \\
\hline Never used the Internet & $7(5.8)$ & $9(10)$ & $0(0)$ & $0(0)$ & $4(28.6)$ \\
\hline
\end{tabular}




\subsection{Perceived Effects of ICT on HIM Practice and Healthcare Service Delivery}

Fig 2 below shows that virtually all the participants across professions (medical laboratory science, 100\%; pharmacy, 100\%; doctors, 97.8\%; nursing, 95.9\% and HIM, 94.7\%) indicated that ICT will improve medical care quality. On whether ICT will enhance confidentiality of patients' health records, nearly all professionals in the study recorded higher responses with HIM professionals with the lowest (78.9\%).

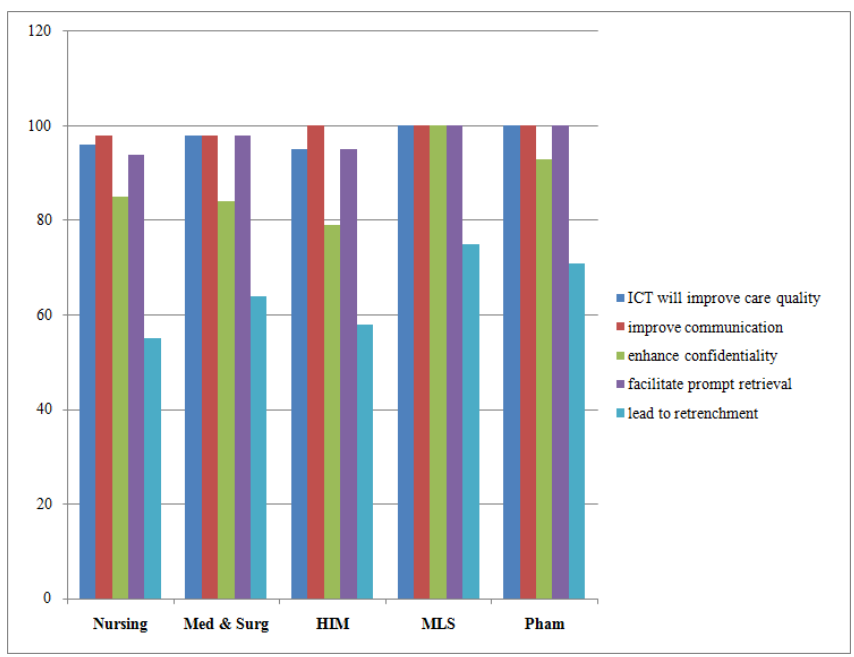

Fig 2. Perceive effects of ICT on healthcare

\section{Discussion}

Improving the health of individuals and communities, and strengthening health systems, disease detection and prevention are crucial to development and poverty reduction. This proposition requires evidence-base medicine (EBM) which demands appropriate and timely acquisition of the best available evidence often offered by ICT in order to answer clinical questions [21]. Widespread adoption of ICT is a key strategy to meet the challenges facing health systems internationally of increasing demands, rising costs, limited resources and workforce shortages. It has been said [22] that if ICTs are actively deployed, healthcare delivery becomes improved and the public health is better for it. In line with this, our study found that the majority of the participants had used ICT facilities with reasonable experience as between 94 and $95 \%$ have used computer and the Internet for more than three years. Our study coincides with other studies [6-9, 2328] that reported good utilization of computer and the Internet. It however established improvement on studies [27] with moderate use and others [12, 29-34] with low utilization of computer and the Internet.

Participants in our study are considerably knowledgeable and skilled especially in the use of electronic mail (52\%) and the Internet $(47 \%)$ mostly through self-efforts. However, there was reported poor knowledge and skills in database design and statistical analysis as between 46 and $48 \%$ could not use the tools at all. These findings correlate with findings by Adeleke et al [9] and Ajuwon \& Rhine [34] where notable number of participants reported that they first learnt ICT through self-efforts. The report on good ICT skill coincides with a study [9] where the majority knew how to use basic ICT applications such as Microsoft Word. Major factors that contributed to the way healthcare professionals in this study utilized computer and the Internet were profession, age, sex and possession of a laptop computer. For instance, all pharmacists had used computer for more than three years and HIM professionals relatively indicated concerns over confidentiality in the wake of ICT application as they recorded the lowest response $(78.9 \%)$ in this regards. Statistically, profession, possession of laptop computer systems, age and sex all had statistical significance $(p=.000)$ on ICT knowledge, skills and perception. Virtually, all healthcare professionals in this study indicated that ICT will improve medical care quality. These findings agree with Adeleke et al [9] where most participants reported positive perceptions about the effects of IT on health information management and healthcare systems and decried the allusions that the emerging technology will dehumanize doctor-patient relationship. However, HIM professionals' relative low rating of ICT as regards confidentiality of patients' health records might mean that this category of participants who have the responsibility to promote the tenets of confidentiality still have some concerns over confidentiality as the country's healthcare systems embrace ICT applications. This is at variant with a study [35] where healthcare professionals including HIM professionals recommended ICT as a measure to ensure confidentiality.

Access to healthcare information has become a key international development issue [36] and improved proficiency in the use of computer and the Internet had been recommended [21] as one way to improve access to invaluable health information among healthcare professionals. It is quite interesting that this current study reveals general quest for further training in the use of computer (86\%), and the Internet $(83 \%)$. The findings on further training in computer and the Internet correspond with previous studies such as Adeleke et al [9] where participants wanted more training in electronic data analysis; Gour et al [37] with much demands on provision for computer training and Cullen [38] with training needs in the identification, use, and application of evidence in practice. Other corroborating reports are Ajayi [39] on how to enhance efficiency in academic pursuance; Yeung [21] on benefits of technology-enabled training; Ajayi [40] on the introduction of health informatics and Chan et al [41] reported that a group of primary care nurses with consensus required training with a view to improving their computer use.

\subsection{Study Limitations}

There was an industrial action at National Hospital Abuja during data collection. Therefore, we had to contend with various setbacks while trying to gather the raw data. In spite of the attrition rate, we could not retrieve all completed questionnaire from the nurses. 


\section{Conclusion}

Healthcare providers at National Hospital, Abuja possess good knowledge, are considerably skilled with good disposition towards computer and use of the Internet especially for the enhancement of their professional practice and improvement of patient care quality. However, they presented poor knowledge in database design and statistical analysis. They massively indicated interests for further training in the use of computer and the Internet so as to boost their sources of information for better practice and improved public health. Any effort at enriching their sources of information and enhancing their usability of these technologies would be worthwhile.

\section{Recommendations}

1. As a step forward to evolve better electronic healthcare environments, which tend to evolve an improved healthcare quality, it is very important that the hospital and other healthcare facilities organize specific and intensive ICT training for their employees and make necessary infrastructures available for the implementations.

2. There is a need for advocacy on the need to embrace health IT among all healthcare professionals at National Hospital and in Nigeria healthcare system as a whole.

\section{Acknowledgement}

The authors wish to appreciate Mr. RA Adio of the Department of Health Records, National Hospital Abuja for his comments at the conception of the study.

\section{References}

[1] J. Murray. Cloud network architecture and ICT. Information and communication technology. Available at: http://itknowledgeexchange.techtarget.com/modern-networkarchitecture/cloud-network-architecture-and-ict/. Accessed on: December 19, 2014.

[2] P. J. Cruickshank. Computer in medicine: patients' attitudes. Journal of Royal College of General Practitioners.1984; 34: 77 -80 .

[3] J. W. Fairley. Computers in medicine. Journal of Royal Society of Medicine.1991; 84: 566 - 567.

[4] Ndunagu, JN. Website Design \& Programming. National Open University of Nigeria (Course Material).2010; pp21.

[5] History of the Internet. Available at: en.wikipedia.org/wiki/History_of_the_Internet.htm. Accessed on: January $10^{\text {th }} 2013$.

[6] I. A. Asangansi, O. O. Adejoro, O. Farri, O. Makinde. Computer use among doctors in Africa: survey of trainees in a Nigerian teaching hospital. Journal of Health Informatics in Developing Countries. 2008; 2(1): 10-14.
[7] I. T. Adeleke, S. A. Erinle, A. M. Ndana, T. C. Anamah, O. A. Ogundele, D. Aliyu. Health information technology in Nigeria: stakeholders' perspectives of nationwide implementations and meaningful use of the emerging technology in the most populous black nation. American Journal of Health Research. Special Issue: Health InformationTechnology in Developing Nations: Challenges and Prospects Health Information Technology. 2015; 3(1-1):17-24. doi: 10.11648/j.ajhr.s.2015030101.13.

[8] I. T. Adeleke, M. A. Asiru, B. M. Oweghoro, A. B. Jimoh, A. M. Ndana. Computer and internet use among tertiary healthcare providers and trainees in a Nigerian public hospital. American Journal of Health Research. Special Issue: Health Information Technology in Developing Nations: Challenges and Prospects Health Information Technology. 2015;3(1-1):110. doi: 10.11648/j.ajhr.s.2015030101.11.

[9] I. T. Adeleke, A. H. Lawal, R. A. Adio, A. A. Adebisi. Information technology skills and training needs of health information management professionals in Nigeria: a nationwide study. Health Information Management Journal, 2014. doi.org/10.12826/18333575.2014.0002.Adeleke.

[10] I. T. Adeleke, A. O. Adekanye, K. A. Onawola, et al. Data quality assessment in healthcare: a 365-day chart review of inpatients' health records at a Nigerian tertiary hospital. Journal of American Medical Informatics Association.2012; 19(6):1039-42. doi:10.1136/amiajnl-2012-000823.

[11] B. Chaudhry, J. Wang, S. Wu, et al. Systematic review: impact of health information technology on quality, efficiency and costs of medical care. Ann Intern Med. 2006; 144:742-752.

[12] B. Wheatley. Transferring care delivery through health information technology. Perm J. 2013; 17(1): 81-86 doi:10.7812/TPP/12-030 PMCID: PMC3627785.

[13] I. S. Bello, F. A. Arogundade, A. A. Sanusi, I. T. Ezeoma, E. A. Abioye- Kuteyi, A. Akinsola. Knowledge and utilization of information technology among healthcare professionals and students in Ile-Ife, Nigeria: A case study of a University teaching hospital. J Med Internet Res. 2004; 6(4): e45.

[14] C. Dee. Information needs of the rural physician: a descriptive study. Bulleting of Medical Library Association. 1993; 81(3): 259-264.

[15] C. Edward, R. Fox, R. Gillard, et al. Explaining health managers" information seeking behaviour and use. Final report. NIHR Service Delivery and Organisation programme; $2013 ; 1-215$.

[16] D. Bereczki. The role of electronic databases in practical decision making in the care of patients with cerebrovascular diseases. Orvos Hetilap 2002; 143:1353-9.

[17] M. A. Winker, A. Flanagin, B. Chi-Lum, et al. Guidelines for medical and health information sites on the Internet: principles governing AMA websites. JAMA.2000; 283(12): 1600 -1606.

[18] R. Kale. Health Information for the developing world. BMJ. 1994; 309: 939- 42.

[19] J. L. Dorsch. Information needs of rural health professionals: a review of literature. Bull Med Libr Assoc. 2000; 88(4): 346-354.

[20] E. Yeung, R. Balogh, D. Cole, D. Jakovic, M. D. Landry. Internet use among community-based rehabilitation workers in Herzegovina: A cross-sectional survey. Physiother Can. 2011; 63(4): 445-452. 
[21] G. Eysenbach. Consumer health informatics.BMJ.2000; 320(7251):1713- 1716.

[22] M. Trivedi, A. Joshi. Computer and Internet use by healthcare professionals in a rural medical college in India. Library Philosophy and Practice.2008; 1-4.

[23] N. A. Ajayi. Information seeking by nurses in the Obafemi Awolowo University Teaching Hospital, Nigeria. Information Development. 2005; 21(2):121-127 doi: $10.1177 / 0266666905054506$.

[24] N. L. Bennett, L. L. Casesbeer, R. E. Kristofco, S. M. Strasser. Physicians' Internet information-seeking behaviours. The Journal of Continuing Education in the Health Professions.2004; 24: 31-38.

[25] N. Bennett, L. L. Casesbeer, R. Kristofio, B. C. Collins. Family physicians' information seeking behaviours: a survey comparison with other specialties. Medical Informatics and Decision Making.2005; 5:9.

[26] S. C. Inamdar, S. B. Rotti. Computer use among medical students in an institution in southern India. Natl Med J India.2004; 17:8-10.

[27] M. McKnight. The information seeking of on-duty critical care nurses: evidence from participant observation and incontext interviews. J Med Libr Assoc. 2006; 94(2): 145-151.

[28] I. T. Adeleke, A. O. Adekanye, A. D. Jibril, F. F. Danmallam, H. E. Inyinbor, S. A. Omokanye. Research knowledge and behaviour of health workers at Federal Medical Centre, Bida: a task before learned mentors. El Mednifico Journal. 2014;2:2.

[29] N. Ameh, T. S. Kene, E. A. Ameh. Computer knowledge among clinical year medical students in a resource poor setting. African Health Sciences. 2008; 8(1): 40-43.

[30] R. Schoenberg, C. Safran. Internet based repository of medical records that retains patient confidentiality. BMJ. 2000; 321(7270): 1199-1203. PMCID: PMC1118958.

[31] G. A. Ajuwon. Computer and Internet use by first year clinical and nursing students in a Nigerian teaching hospital. BMC Medical Informatics and Decision Making.2003; 3:10.

[32] M. Samuel, J. C. Coombes, J. J. Miranda, R. Melvin, E. J. W. Young, P. Azarmina. Assessing computer skills in Tanzanian medical students: and elective experience. BMC Public Health. 2004; 4:37.

[33] G. A. Ajuwon, L. Rhine. The level of Internet access and ICT training for health information professionals in sub-Saharan Africa. Health Information Library Journal. 2008; 25(3):175185.

[34] I. T. Adeleke, A. O. Adekanye, S. A. Adefemi, et al. Knowledge, attitudes and practice of confidentiality of patients' health records among healthcare professionals at Federal Medical Centre, Bida. Nigerian Journal of Medicine. 2011; 20(2): 228-235.

[35] F. Godlee, N. Pakenham-Walsh, D. Ncayiyana, B. Cohen, A. Packer. Can we achieve health information for all by 2015? Lancet.2004; 364: 295-300.

[36] N. Gour, D. Srivastava. Knowledge of computer among healthcare professionals of India: a key toward e-Health. Telemedicine and e-Health. 2010; 16(9): 957-962. doi:10.1089/tmj.2010.0049.

[37] R. J. Cullen. In search of evidence: family practitioners' use of the Internet for clinical information. J Med Libr Assoc. 2002; 90(4): 370-379.

[38] O. A. Salako, M. A. Tiamiyu. Use of search engines for research by postgraduate students of the University of Ibadan, Nigeria. Afr J Lib Arch \& Inf Sc. 2007; 17(2): 103-115.

[39] N. A. Ajayi. Impact of health informatics on nurses' computer skills and the role of the library. Electronic Library, The. 2013; 31(2):157- 166 .

[40] T. Chan, S. Brew, S. D. Lusignan. Community nursing needs more silver surfers: a questionnaire survey of primary care nurses' use of information technology. BMC Nurs.2004; 3: 4.doi: 10.1186/1472-6955-3-4. 